\title{
Cluster Preface: Metathesis Reactions beyond Olefins
}

\author{
Bill Morandi \\ Laboratorium für Organische Chemie, ETH Zurich, \\ Vladimir-Prelog-Weg 3, HCl, 8093 Zürich, Switzerland \\ bill.morandi@org.chem.ethz.ch \\ Published as part of the Cluster Metathesis beyond Olefins
}

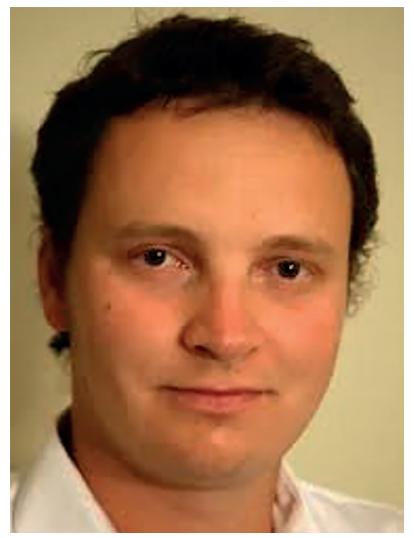

Received: 27.09.2019

Accepted: 27.09.2019

Published online:

DOI: 10.1055/s-0039-1690296; Art ID: st-2019-b6000-c

Bill Morandi studied at the ETH Zurich from 2003-2012, earning a B.Sc. in biology, an M.Sc. in chemical biology and a Ph.D. in organic chemistry working with Prof. Erick M. Carreira. After a postdoc with Prof. Robert H. Grubbs at CalTech, he led an independent Max Planck Research Group from 2014-2018 at the Max-Planck-Institut für Kohlenforschung, Germany. Since July 2018, he is a tenured Associate Professor at the ETH Zurich where he holds a chair in synthetic organic chemistry. His independent research program targets the development of new concepts in catalysis, with a particular emphasis on employing inexpensive and sustainable catalysts to transform broadly available feedstocks, such as polyols and hydrocarbons, into valuable building blocks for applications in medicine and materials science.

The emergence of alkene metathesis has been accompanied with countless synthetic applications across the molecular sciences, from drug synthesis to polymer sciences. ${ }^{1}$ The unique mechanism of this reaction, combined with the outstanding functional group tolerance of modern catalytic systems, has been key to the extremely rapid development of this reaction. Recently, researchers have recognized the potential of developing new metathesis reactions that go beyond the traditional olefin metathesis paradigm, developing several new, mechanistically distinct metathesis reactions which can be used to break and reform other important types of triple, double and single bonds. ${ }^{2}$

In this SYNLETT Cluster, we are delighted to celebrate these new developments by highlighting some new 'metathesis reactions beyond olefins' reported by leading authors in this field of research. The diversity of bonds (e.g., $\mathrm{C}-\mathrm{S}, \mathrm{C}-\mathrm{O}, \mathrm{C}=\mathrm{O}, \mathrm{M}-\mathrm{X}$ ) involved in this cluster as well as the diversity of applications considered (organic synthesis, organometallic synthesis, polymer chemistry and supramolecular chemistry) clearly highlight the untapped potential of this research area.

Recently, carbonyl olefin metathesis has emerged as a useful alternative to traditional carbonyl olefination methods, which are limited by their low atom economy and waste disposal. Lambert has summarized, in a timely review, the recent efforts to turn this new metathesis reaction into a synthetically useful process. ${ }^{3}$ In his review he also describes an ingenious organocatalytic strategy which takes advantage of a simple hydrazine catalyst to realize this challenging transformation. Another exciting manuscript in this area, written by Nguyen et al., describes the use of iodonium species as a new catalyst for ring-closing carbonyl olefin metathesis, thus adding an important new catalytic strategy to the toolbox. ${ }^{4}$

Metathesis reactions do not need to proceed between unsaturated bonds and can thus be extended to single bonds. A classical yet powerful illustration of this concept is salt metathesis, which can readily be used to exchange two $\mathrm{M}-\mathrm{X}$ bonds to synthesize new metal complexes. This concept is illustrated in the manuscript from Grela et al., who used this strategy to access some new Ru carbene complexes. ${ }^{5}$ Due to their abundance in organic molecules, the metathesis of $\mathrm{C}-\mathrm{S}$ bonds has recently emerged as an important frontier area. In this Cluster, Tobisu and Chatani report on a ring-closing $\mathrm{C}-\mathrm{S}$ metathesis, which proceeds in the presence of a suitable thiolate initiator, in order to access synthetically useful dibenzothiophenes. ${ }^{6}$ In another contribution, von Delius et al. have described trithioester exchange and metathesis reactions under acidic activation. ${ }^{7}$ 
This new reaction adds to the toolbox of dynamic covalent reactions available for the thermodynamically controlled synthesis of supramolecular architectures. Reversibly cleaving $\mathrm{C}-\mathrm{O}$ bonds is another attractive target reaction, and Miller and Pemba have contributed to this issue with a kinetic study of the acetal metathesis reaction they developed previously for the synthesis of new polymeric materials. ${ }^{8}$

Finally, Naka and Naraoka report on a different yet similar type of reversible reaction, a reaction which transfers a molecule of water between a primary amide and a nitrile under palladium catalysis. ${ }^{9}$ This shuttle catalysis reaction enables the synthesis of dicarboxamides using the release of volatile acetonitrile as a driving force, providing a mild entry into selective hydrolysis of nitriles.

\section{References}

(1) Handbook of Metathesis; Grubbs, R. H., Ed.; Wiley-VCH: Weinheim, 2003.

(2) Bhawal, B. N.; Morandi, B. Angew. Chem. Int. Ed. 2019, 58, 10074.

(3) Lambert, T. H. Synlett 2019, 30, 1954.

(4) Oss, G.; Nguyen, T. V. Synlett 2019, 30, 1966.

(5) Patrzałek, M.; Piątkowski, J.; Kajetanowicz, A.; Grela, K. Synlett 2019, 30, 1981.

(6) Masuya, Y.; Kawashima, Y.; Kodama, T.; Chatani, N.; Tobisu, M. Synlett 2019, 30, 1995.

(7) Bothe, M.; Orrillo, A.; Gastón, F.; Ricardo, L. E.; von Delius, Max. Synlett 2019, 30, 1988.

(8) Pemba, A. G.; Miller, S. A. Synlett 2019, 30, 1971.

(9) Naraoka, A.; Naka, H. Synlett 2019, 30, 1977. 